\title{
Atos de Leitura na Alfabetização
}

Acts of Reading in Literacy

Actes de Lecture em Alphabétisation

\author{
Márcia Martins de Oliveira Abreu ${ }^{1}$ \\ Universidade Federal de Uberlândia \\ Adriana Pastorello Buim Arena ${ }^{2}$ \\ Universidade Federal de Uberlândia
}

\begin{abstract}
Resumo: Esta publicação deriva da tese de doutorado ${ }^{3}$. $\mathrm{O}$ artigo analisa o ato da leitura na alfabetização e apresenta especificamente uma das estratégias desenvolvidas, intitulada Ler para encontrar. O processo de pesquisa de intervenção foi desenvolvido com uma turma de crianças de seis anos de idade, em um colégio de aplicação de uma Universidade Federal no decorrer do ano letivo de 2016. A pesquisa se propôs a investigar como o envolvimento das crianças com a leitura acontece quando o ato de ler é parte de uma atividade essencial para a criança como é o brincar. Os resultados confirmaram a hipótese de que a aprendizagem da leitura acontece satisfatoriamente quando o professor consegue criar na criança a necessidade de ler os textos propostos.
\end{abstract}

Palavras-chave: Alfabetização. Leitura. Estratégia de leitura.

Abstract: This publication derives from the doctoral thesis. The article analyzes the act of reading in literacy and specifically presents one of the strategies developed, entitled Read to find. The intervention research process was developed with a class of six-year-old children, in an application college of a Federal University during the 2016 academic year. The research aimed to investigate how children's involvement with reading occurs when the act of reading is part of an essential activity for the child, such as playing. The results confirmed the hypothesis that the learning of reading happens satisfactorily when the teacher is able to create in the child the need to read the proposed texts.

Keywords: Literacy. Reading. Reading strategy.

Résumé: Cette publication découle de la thèse de doctorat. L'article analyse l'acte de lire dans l'alphabétisation et présente spécifiquement l'une des stratégies développées, intitulée Lire pour trouver. Le processus de recherche interventionnelle a été développé avec un groupe d'enfants de six ans, dans un collège d'application d'une Université Fédérale au cours de l'année scolaire 2016. La recherche visait à étudier comment l'implication des enfants dans la lecture se produit lorsque l'acte de lire fait partie d'une

\footnotetext{
${ }^{1}$ Doutora em Educação pela Universidade Federal de Uberlândia/MG. E-mail: mmartinsabreu10@gmail.com. Lattes: http://lattes.cnpq.br/0369101697331870. ORCID: https://orcid.org/oooo-0001-8917-6077.

2 Doutora em Educação pela Unesp - Campus de Marília - SP. E-mail: dricapastorello@gmail.com. Lattes: http://lattes.cnpq.br/7122993229219646. ORCID: https://orcid.org/o000-0002-8355-0221.

${ }^{3} \mathrm{ABREU}$, Márcia M. de O. A criança e a apropriação da cultura escrita: uma possibilidade de alfabetização discursiva. 2019. 482 f. Tese (Doutorado em Educação) - Universidade Federal de Uberlândia, 2019. Disponível em: https://repositorio.ufu.br/bitstream/123456789/25067/1/CriancaApropriacaoCulturaV1.pdf(link volume 1) https://repositorio.ufu.br/bitstream/123456789/25067/2/CriancaApropriacaoCulturaV2.pdf (link volume 2).
} 
Revista Educação e Políticas em Debate - v. 10, n. 2, p. 784-800, mai./ago. 2021 - ISSN 2238-8346

activité essentielle pour l'enfant, comme le jeu. Les résultats ont confirmé l'hypothèse que l'apprentissage de la lecture se passe de manière satisfaisante lorsque l'enseignant est capable de créer chez l'enfant le besoin de lire les textes proposés.

Mots clés: Alphabétisation. Lecture. Stratégie de lecture.

Recebido em: 28 de março de 2021

Aceito em: 10 de junho de 2021

\section{Considerações iniciais}

Este artigo terá como suporte teórico os pressupostos bakhtinianos, volochinovianos e vigotskianos, sobre a relação linguagem e pensamento e sobre os diferentes modos de uso da linguagem no contexto desta pesquisa de intervenção. Portanto, o processo de alfabetização será não apenas abordado, mas ainda defendido, com base nas concepções baktinianas e volochinovianas e na abordagem históricocultural. O desenvolvimento humano será visto de forma diretamente relacionado às aprendizagens, e, consequentemente, portanto, entender-se-á que o ensino se configura como importante elemento no processo de desenvolvimento no contex to escolar.

Tanto a história como a cultura se caracterizam como dois conceitos fundamentais na abordagem histórico-cultural que se constituiu acerca do estudo do homem, que se encontra em permanente transformação, por meio das suas relações com os instrumentos culturais, tendo por base o materialismo histórico-dialético. Essa transformação, vivenciada pelo homem no decorrer do seu desenvolvimento, que o torna humano, é também histórica.

Neste sentido, acredita-se que todo o processo de desenvolvimento do homem esteja relacionado à aprendizagem. Por meio do que se aprende, em todas as relações, que o homem vai criando condições de avanços para o seu singular desenvolvimento. Portanto, é na relação com o outro que o homem aprende e se desenvolve, por isso mesmo, a presença do outro, bem como a sua participação no desenvolvimento se configura como primordial.

A interação, de forma especial a que ocorre entre indivíduos face a face, tem uma função fundamental no processo de internalização. Ao tratar sobre a relação entre a aprendizagem e o desenvolvimento, Vigotski (2009, p. 334) afirma:

[.... a aprendizagem e o desenvolvimento não coincidem imediatamente mas são dois processos que estão em complexas inter-relações. A aprendizagem só é boa quando está à frente do desenvolvimento. Neste caso, ela motiva e desencadeia para a vida toda uma série de funções que se encontravam em fase de amadurecimento e na zona de desenvolvimento imediato. É nisto que consiste o papel principal da aprendizagem no desenvolvimento. 
Revista Educação e Políticas em Debate - v. 10, n. 2, p. 784-800, mai./ago. 2021 - ISSN 2238-8346

Assim como Vigotski valoriza a relação com outro apontando a aprendizagem como verdadeira propulsora do desenvolvimento humano, Bakhtin também contribui com essa concepção. Ao se referir ao dialogismo presente em todo o decorrer da existência humana, confere a presença do outro e especialmente à presença de suas palavras grande importância para todo o processo de monologização que posteriormen te resulta na consciência criadora. Para Bakhtin (2003, p. 404),

A consciência criadora monologizada une e personifica frequentemente as palavras do outro, tornadas vozes alheias anônimas, em símbolos especiais: "voz da própria vida", "voz da natureza", "voz do povo", "voz de Deus", etc. Papel desempenhado nesse processo pela palavra dotada de autoridade, que habitualmente não perde seu portador, não se torna anônima.

Dessa forma, entende-se que estes dois pensadores, contribuem para a certificação de que ninguém se desenvolve sem o outro. Mesmo em vertentes historicamente diferenciadas, pode-se afirmar que o outro, para os dois autores, são essenciais ao desenvolvimento humano.

Com base nas afirmativas dos autores supracitados, acredita-se que a escola poderia contribuir, de forma mais eficaz, com as aprendizagens dos alunos, substituindo as tentativas de mensuração do que eles aprenderam ou não sobre o que foi oferecido, pela valorização de propostas em que os alunos sejam realmente engajados. Por meio de atividades significativas, o ensino poderia ser pensado com o objetivo de criar condições propícias de aprendizagens, que realmente impulsionassem os alunos.

As situações de aprendizado que provoquem reais e significativos avanços são aquelas em que o aluno é colocado numa zona de desenvolvimento em que ele é capaz de entender um problema e se desenvolver. A partir deste novo desenvolvimento, funções que estavam quase aparecendo, mas ainda não teriam surgido, aparecem indicando que houve desenvolvimento e, a partir deste ponto, o professor pode propiciar novas aprendizagens.

Pode-se dizer que os resultados da realização do ensino mesmo estando condicionados às condições e à participação dos alunos precisam ser pensados com vistas ao desenvolvimento de sujeitos concretos, com suas peculiaridades, para que todos e cada um, no contexto da sala de aula, tenham condições de se desenvolverem.

Especialmente no contexto da alfabetização, por meio do processo de apropriação da língua escrita, é mobilizado um trabalho simbólico na apropriação deste instrumento que interfere de forma significativa nos modos de pensar, de falar e de agir. Assim, a escrita como instrumento simbólico, produzido na história e na cultura, possui o poder de transformar o funcionamento mental do sujeito, potencializando-o e provocando o desenvolvimento de novas 
Revista Educação e Políticas em Debate - v. 10, n. 2, p. 784-800, mai./ago. 2021 - ISSN 2238-8346 funções. Cabe à escola oferecer situações de aprendizagem que desafie e impulsione a apropriação de outros conhecimentos.

No caso da língua escrita, entende-se que é a partir dos conhecimentos prévios que as crianças apresentam que o alfabetizador organiza um ensino que permita novas experiências, novas aprendizagens, que possibilitarão o desenvolvimento das competências leitoras e escritoras.

Nesse caso, não caberiam práticas alfabetizadoras com textos esvaziados tanto de sentido como da necessidade de utilização e de produção. Sobre o uso de textos artificiais utilizados em contextos desprovidos da dialogicidade e da discursividade, Arena (2009, p.170) esclarece que

A apresentação de textos simplificados e artificialmente inventados dá a falsa idéia de que a escola estaria realizando uma aproximação entre o aluno e a língua escrita, de maneira que a apropriação se fizesse completamente. Há, em sintonia com o que venho comentando, uma contradição nessa conduta, porque a aproximação deveria dar-se na direção da língua viva, usada no cotidiano, trazendo com ela o que dela não poderia ser apartado: os matizes ideológicos, a contextualização, as suas finalidades e funções, a necessidade de uso.

Mesmo partindo da premissa de que a linguagem escrita se constitui como um recurso humano utilizado cotidianamente nos mais diversos setores da sociedade impregnada de todas suas matizes, percebe-se muitas vezes que as práticas docentes, especialmente nos anos iniciais do Ensino Fundamental, tendem a planejar e efetivar ações acerca dos processos de ensino e de aprendizagem da escrita, de forma que a própria apropriação do sistema de escrita, bem como sua utilização, fique bastante limitada às atividades desenvolvidas na e pela escola, criando um pensamento equivocado de que o lugar da leitura e da escrita se restringe apenas à escola e não às diversas ações dos sujeitos no mundo.

A alfabetização é um período propício para a participação em experiências que incentivarão o aluno a querer a aprender e a se desenvolver cada vez mais. O processo de alfabetização se configura como primordial para a realização de mudanças significativas no desenvolvimento infantil tendo em vista que, por meio dele e a partir dele, os alfabetizandos terão possibilidades de acesso a diferentes culturas.

Ao dominar a língua escrita, assim como quando começa a falar, a criança passa a se envolver também em atividades que antes não se envolvia por meio de um recurso que até então ela não dominava. A alfabetização, então, se define como um momen to de novas possibilidades de aprendizagens e, consequentemente, de novos processos de desenvolvimento pelo fato de ela conseguir um novo canal de comunicação com o mundo 
Revista Educação e Políticas em Debate - v. 10, n. 2, p. 784-800, mai./ago. 2021 - ISSN 2238-8346 onde habita, por meio do seu acesso à cultura escrita que possui uma conotação ampla, que vai muito além da simples decifração de símbolos.

Neste artigo, a alfabetização é concebida como um processo que vai muito além do simples reconhecimento de letras que sirvam para nomear os elementos do mundo, mas sim é um processo fundamental para o desenvolvimento do aluno como instrumento para sua formação humana, em que por meio dele os sujeitos são capazes de se transformarem, inferindo em seus próprios processos de formação, por meio de sua apropriação e utilização.

Assim, compreende-se a alfabetização como um desafio, no entanto, com a mesma intensidade de sua complexidade ela também é entendida como potencializadora de processos de transformação. Processos estes que possibilitam ao aluno, aprender a se autotransformar por meio do acesso efetivo ao mundo da escrita tendo condições de pensar, crescer e se desenvolver por meio dos mais diversos usos da linguagem escrita em todos os contextos de sua existência.

Enfim, o desafio necessário a se enfrentar é o desenvolvimento de processos de alfabetização que possibilitem aos alunos, durante a aprendizagem da escrita e da leitura refletir, significar, expor, criticar, apontar seus pontos de vistas, negociar situações, enfim, que oportunizem as crianças a vivenciar esse processo de forma significativa e também consigam se ressignificar por meio do domínio desta forma de linguagem presente tão fortemente nas sociedades letradas. Dessa forma, à medida que vão se apropriando do conhecimento sobre a linguagem escrita, ao mesmo tempo em que se apropriam do objeto que é da cultura, elas se transformam e ao mesmo tempo a transformam.

\section{Leitura: um processo de construção de sentidos}

Após uma breve discussão teórica sobre como concebemos o processo de alfabetização, passaremos agora a discutir o ensino da leitura nesse período escolar específico, foco central deste artigo. Partiremos do pressuposto de que "[ [...] ler é tomar conhecimento de um texto gráfico" (BAJARD, 2007, p. 24), que “[ [...] a forma é orientada pelo contexto" (VOLOCHÍNOV, 2017, p. 179).

Mediante essas convicções é que se considerou que a apreensão do ato de ler pela criança não poderia acontecer apenas por meio do ensino da técnica do sistema de escrita, mas no próprio uso da linguagem materializada na forma de enunciados, orais e escritos, em situações concretas. Para se apropriar da leitura era necessário que as crianças lessem.

As teorias bakhtiniana e volochinoviana ampararam essa pesquisa de intervenção na medida em que concebem o uso da linguagem em movimento, especificando as 
Revista Educação e Políticas em Debate - v. 10, n. 2, p. 784-800, mai./ago. 2021 - ISSN 2238-8346

minúcias que permeiam o dialógico processo de interação com o outro. De forma especial, o ato de ler apresenta o diálogo dos alunos com o outro em suas diversas práticas de leitura. Diálogos construídos nas relações com os livros, com os autores, com os colegas de sala, com as histórias trocadas, somadas, divididas, redimensionadas, vividas, representadas, indicadas, compartilhadas.

Numa perspectiva bakhtiniana, acredita-se que o ato da leitura se apresenta como uma oportunidade ao leitor de realizar uma interpretação singular e subjetiva numa relação dialógica, em que o conteúdo textual é expresso de forma que o autor se mostra no todo da obra e, ao mesmo tempo, o sentido dela se torna eternamente inacabado.

As possibilidades de atribuição de sentido na ação de ler se tornam inúmeras, tendo em vista este ato se manifestar de forma plural, complexo e criador. Nas palavras de Bakhtin (2003, p. 398),

Definição de sentido em toda a profundidade e complexidade de sua essência. A interpretação como descoberta da presença por meio da percepção visual (contemplação) e da adjunção por elaboração criadora. Antecipação do contexto em expansão subsequente, sua relação com o todo acabado e com o contexto inacabado. Tal sentido (no contexto inacabado) não é tranquilo e nem cômodo (nele não se pode ficar tranquilo nem morrer) (Grifo do autor).

O leitor, ao ler o texto, reelabora a palavra do outro e ao mesmo tempo seus pensamentos, ele realiza um papel não de simples tradutor da mensagem manifestada por meio da escrita, mas de interpretador ativo e criativo. Há uma complexidade envolvida nesse ato, há dialogicidade presente na relação do leitor frente ao texto. A subjetividade humana também é construída de maneira vinculada às leituras e experiências já vivenciadas pelo sujeito.

O autor contribui, ainda, com a discussão sobre a leitura ao apresentar o conceito de polifonia existente no interior de um texto literário que apresenta as diversas vozes controversas. Sendo assim, dentro da organização interna de um discurso existirá sempre a presença de outras obras, de outros textos, enfim, outras leituras. Bakhtin (2003, p. 403) afirma:

O que importa é o tom, separado dos elementos fônicos e semânticos da palavra (e de outros signos). Estes determinam a complexa tonalidade da nossa consciência, tonalidade que serve de contexto axiológicoemocional na nossa interpretação (plena e centrada nos sentidos) do texto que lemos (ou ouvimos), bem como em uma forma mais complexa e no processo de criação (de geração) do texto.

O ato de ler é visto como um processo dialógico de interação entre o autor e o leitor, em que a palavra idealizada para determinado público, ao ser escrita, poderá se definir de uma determinada maneira, com uma determinada intencionalidade e, ao ser lida, poderá ganhar sentidos diferentes. Ao ler um texto, o leitor amplia, aumenta, diversifica, e transforma o seu contexto extratextual, pois a leitura apresenta possibilidades diversas de interpretações no ato de ler. 
Nessa perspectiva, a leitura pode sofrer interferências marcantes devido à composição do universo interior de cada leitor. Segundo Volochínov (2014, p. 117),

O mundo interior e a reflexão de cada indivíduo têm um auditório social próprio bem estabelecido, em cuja atmosfera se constroem suas deduções interiores, suas motivações, suas apreciações, etc. Quanto mais aculturado for o indivíduo, mais o auditório em questão se aproximará do auditório médio da criação ideológica, mas em todo caso o interlocutor ideal não pode ultrapassar as fronteiras de uma classe e de uma época bem-definidas.

Em consonância ainda com essa concepção volochinoviana, acredita-se que, por meio da relação dialógica estabelecida no ato da leitura a cada experiência do leitor com um determinado registro escrito, essa relação seja dialogicamente única e produza um novo texto, a partir de um novo olhar, uma nova leitura, carregada de atribuiçõ es de sentidos individuais e específicos de cada leitor.

Desse modo, no ato de ler, estaria presente o inacabamento infinito do texto, marcado pela interação entre as ideias expressas na escrita e aquele que lê. A cada encontro entre texto e leitor surge a criação de um novo discurso, e a cada vez que isso ocorre o contexto extratextual do leitor é alterado.

Considera-se que no ato da leitura de uma produção gráfica, é conferido ao leitor, um sentido que é único, porque a relação do texto com o contex to também se dará de forma singular. É nessa medida que um mesmo registro pode ser interpretado, compreendido e fazer um sentido diferente para os mais diversos leitores ou, ainda, um mesmo leitor atribuir múltiplos sentidos a um mesmo texto lido em variados momentos de sua vida.

Desde a sua criação, a leitura assume, nos diferentes setores da sociedade, as mais variadas funcionalidades, de acordo com a forma com que cada cultura se apropria desse sistema, no atendimento de suas especificidades e necessidades. Historicamente, o ato de ler tem sido cada vez mais solicitado pelo próprio desenvolvimento das sociedades letradas. Com o aperfeiçoamento das formas de se propagar a escrita, através da evolução dos mais diversos recursos e suportes: livros, revistas, jornais, dispositivos tecnológicos, essa ferramenta tem se transformado e, concomitantemente, modificado os contextos em que é utilizada, cada vez mais.

Mediante essas observações, acredita-se que é na ação concreta de leitura, na interação direta com os textos escritos, que o sujeito se torna leitor. De acordo com Jolibert (1994, p.14),

É lendo que nos tornamos leitor e não aprendendo primeiro para poder ler depois: não é legítimo instalar uma defasagem, nem no tempo nem na natureza da atividade, entre "aprender a ler" e "ler". Colocada numa situação de vida real em que precisa ler um texto, ou seja, construir seu significado 
Revista Educação e Políticas em Debate - v. 10, n. 2, p. 784-800, mai./ago. 2021 - ISSN 2238-8346

(para sua informação ou prazer), cada criança mobiliza suas competências anteriores e deve elaborar novas estratégias para concluir a tarefa.

A consideração da autora contribui com a reflexão no sentido de alertar que muitas vezes no processo de apropriação da linguagem escrita o alfabetizador, na organização de seu trabalho, acaba por materializar uma separação entre as atividades de aprendizagem da escrita e as de sua utilização.

Nesse contex to, o processo de produção de conhecimento sobre o funcionamento da língua escrita se configura de maneira fragmentada, muitas vezes mecânica, impedindo a realização de um trabalho em que o aluno alcance a apropriação dessa forma de linguagem pelo seu uso real, contextualizado e significativo. Ao contrário, se aos alunos fossem oportunizadas situações diretas com textos escritos, e ainda um trabalho de discursividade sobre os mesmos, a prerrogativa aprender a ler lendo seria conquistada na ação. E foi com essa perspectiva que a estratégia Ler para encontrar se desenvolveu.

No processo de leitura, o leitor, por mais novo que seja, em interação com o texto escrito estabelecerá um processo de construção de sentido, fruto não apenas da subjetividade do sujeito, mas também da essência do texto. Enfim, o que definirá o ato de ler será o diálogo entre o leitor e o texto. Nesse processo dialógico sempre haverá, de acordo com Volochínov (2017, p. 204-205), dois elementos que se interagem. Para ele,

Efetivamente, o enunciado se forma entre dois indivíduos socialmente organizados, e, na ausência de um interlocutor real, ele é ocupado, por assim dizer, pela imagem do representante médio daquele grupo social ao qual o falante pertence. A palavra é orientada para o interlocutor, ou seja, é orientada para quem é esse interlocutor (Grifo do autor).

No entanto, apesar de a linguagem escrita estar presente nas sociedades letradas nos mais diversos tipos de atividades humanas, sua presença na vida dos sujeitos não garante que a leitura se realize de forma concreta, real, dialógica e significativa para eles. Mesmo imersos num universo permeado por sinais gráficos, muitas vezes, a real leitura não se concretiza pelo sujeito de forma refletida com a sua função transformadora.

A escola, às vezes, não estimula a função interativa das práticas de leitura, priorizando as atividades silenciosas, muitas vezes desmotivadoras dos alunos que acabam por gerar a aversão dos educandos ao mundo dos livros ou ainda estimulando o pensamento equivocado de que a leitura está a serviço das atividades escolares. Essa forma de conceber e tratar a leitura na escola é preocupante, pois revela o equívoco conceitual de que " $[\ldots]$ a leitura e a escrita se apresentam como uma necessidade mais para a escola do que para a vida" (ABREU, 2012, p.150). 
Revista Educação e Políticas em Debate - v. 10, n. 2, p. 784-800, mai./ago. 2021 - ISSN 2238-8346

Foi com base nessas premissas que a pesquisa se propôs a pensar, idealizar e efetivar uma possibilidade metodológica de alfabetização que oportunizasse às crianças a apreensão do ato cultural de ler por meio da leitura de diversos gêneros textuais, em que pudessem aprender a ler lendo, no movimento de apreensão dos sentidos. Mesmo consciente de que o ato da leitura perpassaria por todos os momentos dos sujeitos, dentro e fora do contex to escolar, considerou-se necessário planejar estratégias específicas que mediariam a relação dos sujeitos com os textos.

Por isso, no planejamento das situações que envolveram a leitura esteve presente a intencionalidade de organização do tempo e do espaço para o ato de ler de diferentes maneiras no contexto da sala de aula.

\section{Ler para encontrar}

Com a convicção de que “[...] ler é construir ativamente a compreensão de um texto, em função do projeto e das necessidades pessoais do momento [...]” (JOLIBERT; JACOB, 2006, p. 183) e ainda pensando que a necessidade e o interesse das crianças pela leitura precisam estar presentes no cotidiano da alfabetização, pela importância que ela apresenta na constituição de sujeitos leitores, é que foi idealizada a estratégia específica, ler para encontrar, que será descrita e analisada neste item.

Inicialmente, foi dito aos alunos que eles deveriam procurar na escola algumas pistas, pequenos textos escritos e escondidos em determinados lugares. Essas pistas os levariam a um local onde eles encontrariam suas produções, ou seja, um livreto que continha tanto os desenhos como as produções escritas de todas as crianças, desenvolvidas em um projeto específico de aprendizagem. Nas orientações dadas, foi indicado que as crianças deveriam procurar pistas para encontrar ao final um tesouro, que havia sido escondido em algum lugar da escola, mas não foi falado que eram as suas próprias produções. Somente após a experiência vivida é que as crianças puderam verificar o que era o tesouro.

As produções, envolvidas nesse processo de procura por meio da leitura, foram construídas no decorrer de um trabalho com gêneros textuais. Esses livretos foram: Tirinhas e Histórias em Quadrinhos de 1 página do $1^{\circ}$ ano, construído no decorrer do trabalho com o gênero textual História em Quadrinhos; Era uma vez um monstro, inspirado na leitura da obra: Monstruosidades de Elias José; Fabulário do $1^{\circ}$ ano, produzido ao final do trabalho realizado com o gênero textual Fábula e Contos de Fadas do $1^{o}$ ano, elaborado no decorrer do trabalho com o gênero Contos de Fadas. 
Imagem 1: Livretos envolvidos no processo de procura

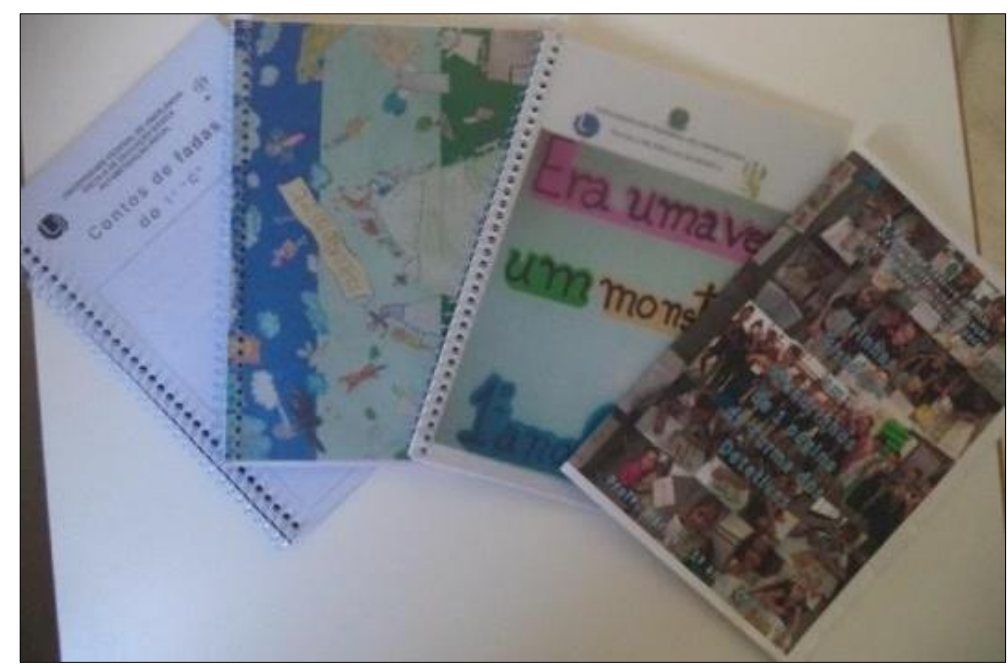

Fonte: Arquivo pessoal da pesquisadora.

O envolvimento dos sujeitos com a produção foi tão intenso que na busca por uma forma especial de entrega do material, composto por todas as produções de HQs reproduzidas em um só suporte, motivou a idealização dessa estratégia, que depois foi realizada em mais outros três momentos posteriores.

A primeira situação em que se materializou a estratégia foi no contexto do trabalho com o gênero textual História em Quadrinhos. Primeiramente, foram elaborados pela professora pequenos textos que contemplavam aspectos físicos de determinados lugares ou ainda objetos pertencentes a alguns espaços específicos da escola, para que, por meio da leitura, as crianças conseguissem associar qual objeto ou lugar era aquele indicado no texto escrito. Após a elaboração desses pequenos textos, os quais foram denominados de pistas, conforme já anunciado, eram colocados nos locais e nos objetos escolhidos. Dessa forma, ao ler o texto e encontrar o local ou o objeto, lá estaria o próximo texto/pista que indicava o próximo local ou objeto e assim sucessivamente. Logo após as orientações, a primeira pista sempre era lida pelos alunos na sala a qual os levariam às demais, de forma consecutiva.

O livreto Tirinhas e Histórias em Quadrinhos de 1 página foi produzido no trabalho pedagógico realizado com as HQs e os alunos estavam muito envolvidos com as produções de Maurício de Sousa. Mediante esse interesse, juntamente com as orientações iniciais sobre a atividade, foi apresentado um cartaz com os principais personagens da Turma da Mônica para os alunos realizarem a leitura da contextualização da atividade inserida no cartaz, conforme demonstra a imagem abaixo. 
Imagem 2: Cartaz de apresentação do primeiro Ler para encontrar

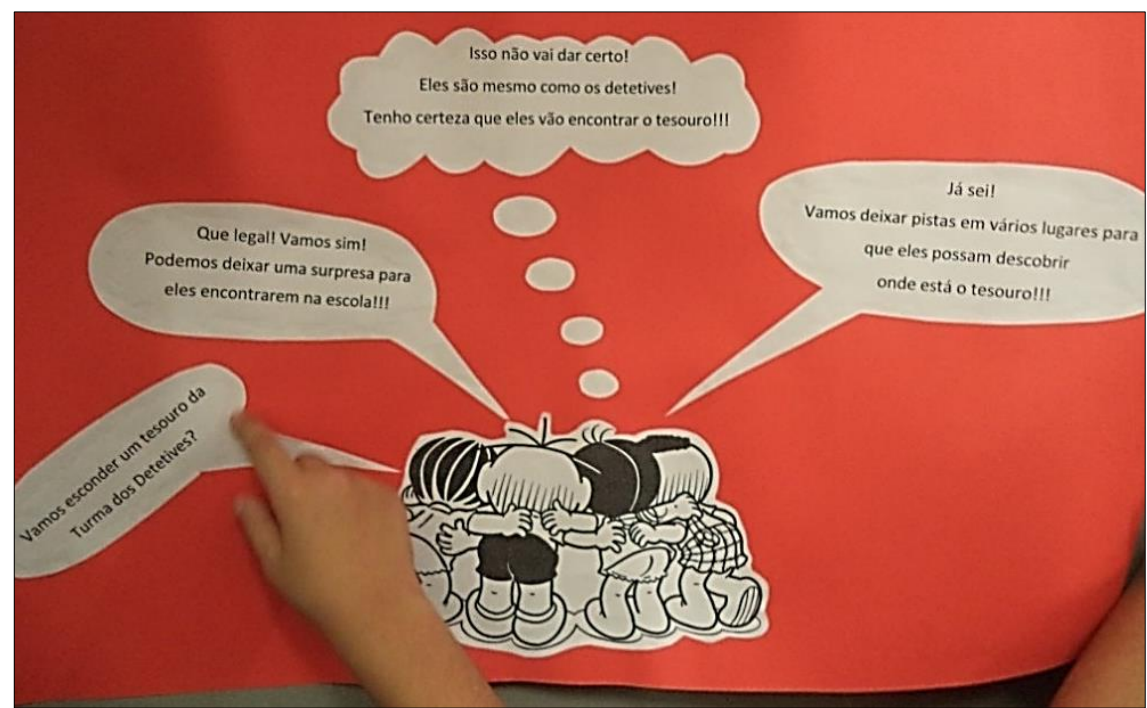

Fonte: Arquivo pessoal da pesquisadora.

Após a apresentação das orientações e acordo sobre as regras, um aluno foi sorteado para realizar a leitura da primeira pista. Elas eram apresentadas impressas em forma de fichas que foram dobradas e afixadas em determinados locais, conforme já anunciado, de forma não muito visível, para que os alunos pudessem encontrá-los. As imagens abaixo demonstram as pistas elaboradas.

Imagem 3: Fichas com as pistas do primeiro Ler para encontrar

$1^{\text {a }}$ pista lida na sala de aula:
Atenção! Para encontrar o tesouro escondido na escola vocês terão que encontrar e ler as pistas. Vai
aí a $1^{a}$ pista:
Sou de forma quadrada,
faço barulho de hora marcada,
toco para avisar que é recreio,
saída dos alunos e entrada!
(Objeto: Aparelho do sinal da portaria da escola)

\begin{tabular}{|c|}
\hline $2^{\text {a }}$ pista afixada no sinal: \\
Fico em um lugar especial da escola, \\
onde todos vão para ler, \\
sou fofinho e de cor laranja, \\
em mim todos sentam pra valer! \\
(Local: Sofá individual da biblioteca) \\
\hline
\end{tabular}

\begin{tabular}{|c|}
\hline $3^{\text {a }}$ pista afixada no sofá da biblioteca: \\
Para que todos nos vissem \\
fomos coladas no cartaz do corredor \\
atrás dele tem uma pista, \\
vocês nos coloriram com muito amor! \\
(Cartaz com as imagens das caveiras por eles pintadas do painel do corredor) \\
\hline
\end{tabular}

\begin{tabular}{c}
\hline $4^{\text {a }}$ pista afixada atrás do cartaz do corredor: \\
Fico num lugar especial da escola, \\
Que você só vai se tiver machucado, \\
Sirvo para pesar as pessoas, \\
Com minha ajuda e da (nome da enfermeira) você poderá ser pesado! \\
\hline
\end{tabular}


Revista Educação e Políticas em Debate - v. 10, n. 2, p. 784-800, mai./ago. 2021 - ISSN 2238-8346

(Objeto: balança da enfermaria)

$5^{a}$ pista afixada na balança da enfermaria:

Sou cinza e tenho várias portas,

Estou no corredor da Educação Infantil,

Dentro de uma de minhas portas,

Tem uma pista que vale por mil!

(Local: Dentro de uma das portas do armário do corredor da Educação Infantil)

\begin{tabular}{|c|}
\hline $6^{\text {a }}$ pista afixada dentro da porta do armário: \\
Sou branco e feito de madeira \\
Fico num lugar em que todos param \\
Porque já subiram ou vão descer a escada \\
Sirvo para as pessoas se sentarem! \\
(Local: banco próximo a escada que liga o primeiro piso da escola à cantina) \\
\hline
\end{tabular}

\begin{tabular}{|c|}
\hline $7^{\text {a }}$ pista afixada no banco: \\
Estou na parede da sua sala \\
Sou feito de plástico e de pano \\
Tenho o nome de todos da turma \\
E aviso quem falta durante todo o ano! \\
(Objeto: Painel de chamada da sala) \\
\hline
\end{tabular}

$8^{\text {a }}$ pista afixada atrás do painel de chamada:

Estou dentro de uma porta,

Com o cartaz de uma música

Sobre alguém que se deu mal e todo mundo riu

Porque seu dente ficou mole, mole e caiu!

(Porta 6 do armário com a letra da música Dente por dente do Cocoricó)

(Mensagem afixada na embalagem com os livretos de HQs da turma)

Turma dos Detetives,

vocês acabam de encontrar o tesouro da turma!

São as histórias em quadrinhos

que vocês construíram!

Parabéns!!!!!

Assinado: Turma da Mônica - 21/06/2016

Fonte: Elaboração própria.

Imagem 4: Registros da leitura e dos locais das duas primeiras e última pistas

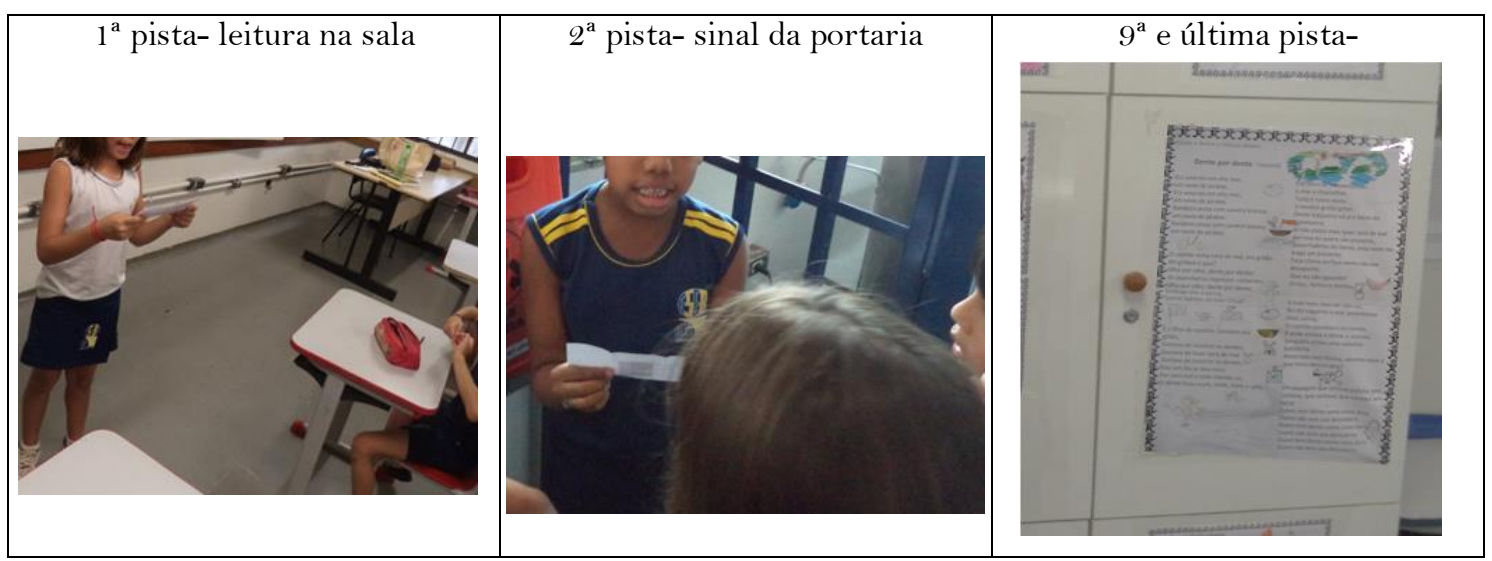

Fonte: Arquivo pessoal da pesquisadora. 
A escolha dos elementos presentes nas pistas elaborados em todas as vezes que ocorreram a estratégia Ler para encontrar se constituíram de aspectos significativos para os sujeitos. Eram locais e objetos muito familiares e ainda elementos não só conhecidos pelas crianças, mas com os quais elas tinham estabelecido já uma relação significativa.

$\mathrm{O}$ envolvimento e a participação das crianças nessa atividade superaram as expectativas. A tentativa de saber o que o tex to apresentava que os levariam à próxima pista e, ao final, os levariam ao tesouro foi um elemento desencadeador do desejo, do motivo e da necessidade tão reafirmada por Jolibert como necessárias no processo de leitura. Ao definirem a leitura como interrogação de textos, Jolibert e Jacob (2006, p. 53) contribuem com a discussão da seguinte forma,

Falar em "interrogar" um texto, em vez de apenas "lê-lo" ou "lê-lo de maneira
interpretativa" é uma maneira de enfatizar o que agora sabemos sobre o
processo de leitura - e de explicitar o que as crianças têm de aprender, desde
a educação infantil, para aprender a ler. Se ler é interrogar um texto em
função de um contexto, de um propósito, de um projeto, para dar resposta a
uma necessidade, então corresponde a uma interação ativa, curiosa, ávida,
direta, entre um leitor e um texto.

Outro aspecto que ficou evidenciado nessa atividade foi que mesmo a leitura sendo pensada como um processo de ordem cognitiva, ela envolveu outros aspectos de ordem sócio afetivos, conforme revelou uma das situações de diálogo registrada entre dois alunos, após o término da atividade.

A. P.: A hora que eu achei a pista do banco eu ia ler M., por que você não esperou?

A. M.: Desculpa! É que todo mundo queria saber onde estava a outra pista e você estava demorando, aí me deu muita vontade de ler para todo mundo saber logo onde estava a outra pista. A. P.: Mas é porque eu estava vendo o que estava escrito. Se você não tivesse lido na minha frente eu tinha lido!

A. M.: A professora falou que depois vai ter de novo, aí se você achar a pista eu deixo você ler, tá?

A. P.: Mas e se eu não conseguir achar? Ou se outros quiserem ler na minha frente?

A. M.: Eu te ajudo a achar e peço para todo mundo esperar você ler, tá bom assim?

A. P.: Vocêpromete?

A. M.: Prometo!

A. P.: Então eu vou confiar!

(Nota de campo: 21/06/2016).

As falas acima demonstram claramente que a relação estabelecida entre os sujeitos, na atividade que envolvia a leitura, não possui apenas um teor cognitivo, mas também o envolvimento de aspectos socioafetivos tais como a frustração, a ansiedade, a expectativa, a curiosidade e até mesmo a cumplicidade que foram suscitadas nos sujeitos por meio da atividade.

A forma de condução da atividade foi sendo modificada juntamente com os sujeitos de acordo com as discussões que ocorriam posteriormente. As regras foram sendo 
Revista Educação e Políticas em Debate - v. 10, n. 2, p. 784-800, mai./ago. 2021 - ISSN 2238-8346 reelaboradas a partir da primeira experiência conforme as necessidades que foram surgindo, as observadas pela professora e as sentidas e expressadas pelos alunos. Mello (2010, p. 184-185) ajuda a pensar sobre a participação deles na forma de organização do trabalho pedagógico. Para ela estar em atividade

Significa a criança saber o que está fazendo, para que faz e estar motivada pelo resultado daquilo que realiza. Quanto maior for a participação da criança na escola dando a conhecer suas necessidades de conhecimento [...] enfim, quanto maior a presença intelectual da criança na escola, maior a possibilidade de que a tarefa proposta se configure como uma atividade significativa para a criança.

Foi assim que a participação ativa dos sujeitos com suas expressões na referida atividade foram contribuindo para o aprimoramento dessa estratégia.

Ao pensar nos dois objetivos: a entrega das produções escritas de forma significativa e a organização de uma situação em que as crianças necessitassem ler, numa situação real de uso da língua escrita, foi que surgiu a elaboração da estratégia no percurso investigativo. Jolibert e Jacob (2006, p. 183) afirmam que

Ler é ler de saída compreensivamente, desenvolvendo - em uma situação real de uso - uma intensa busca do sentido do texto. É uma atividade complexa de tratamento de várias informações por parte da inteligência. É um processo dinâmico de construção cognitiva, ligado à necessidade de atuar, na qual também intervém a afetividade e as relações sociais.

Nessa perspectiva, ficou evidente que o ato de ler enunciados completos e significativos exerce influência em diferentes aspectos da vida humana. Aos poucos, as crianças foram demonstrando cada vez mais o interesse pela linguagem escrita, não apenas no sentido de desejarem ler, mas também de escrever. Esse fato se revelou com clareza na fala abaixo, ocorrida após a terceira experiência com essa estratégia.

A. F.: Professora, você depois você faz mais caçadas com a gente?

P.: Caçadas?! Não entendi! Do que você está falando?

A. F.: Daquela caçada que a gente tem que ir lendo as pistas até achar o tesouro.

P.: A entendi! Faço sim F. você gostou, né?

A. F.: Gostei. E o nosso livro de contos de fada já está quase pronto. Aí a gente vai poder caçar até achar os nossos contos de fadas, não é?

P.: É verdade!

(Nota de campo: 11/05/2016).

As falas do aluno $\mathrm{F}$ revelam que a atividade de leitura havia, de forma dinâmica, sido tomada para ele como importante ao ponto de que a escrita estava sendo realizada pensando no que viria posteriormente, ou seja, a "caçada", por ele assim nomeada.

Ao escrever o conto de fadas, o aluno já tinha em mente que sua produção escrita, juntamente com as dos colegas, seria depois procurada pelos espaços da escola. Portanto, a 
atividade, mesmo sendo idealizada para estimular o ato de ler, como envolveu as produções escritas, estimulou também o ato de escrever.

Sendo assim, a "caçada com pistas", nomeada como Ler para encontrar, mesmo não sendo planejada antes da ida a campo, com sua elaboração e realização com as crianças, demonstrou que a intencionalidade de estimular a leitura foi atingida também por meio dessa estratégia. Além de proporcionar a ação de ler para encontrar, também oportunizou a escrita de uma forma significativa. Smith (1989, p. 246), ao discutir o papel dos professores quanto ao estímulo à leitura, afirma:

O papel primário dos professores de leitura pode ser resumido em poucas palavras - é o de garantir que as crianças tenham demonstrações adequadas da leitura sendo usada para finalidades evidentemente significativas, e ajudar os alunos a satisfazerem, por si mesmos estas finalidades. Onde as crianças vêem pouca relevância na leitura, então os professores devem mostrar que esta vale a pena. Onde as crianças encontram pouco interesse na leitura, os professores devem criar situações interessantes.

Pode-se concluir que uma atividade em que o sujeito utiliza a leitura na busca de um objetivo específico, seja ele qual for, mas que esteja em foco a apreensão do sentido expresso em um enunciado com uma função, aí estará materializado o verdadeiro ato de ler.

Seja para informar, formar, entreter, registrar, socializar, justificar ou lembrar, independentemente da funcionalidade que a leitura assuma em determinado contexto, é importante que ela seja sentida como necessária ao sujeito que lê. Somente assim, a leitura cumprirá com a sua função de atender às necessidades do homem dando cada vez mais condições para que ele a transforme e se transforme por meio de seu uso. Mediante essa convicção, o processo de ensino focado no funcionamento da língua escrita, descolado da sua real função, que é a apreensão de sentidos, não pode ser chamado de leitura.

Jolibert (1994), ao sistematizar a obra Formando Crianças Leitoras, ajuda ainda a pensar que a leitura que faz sentido, também na escola, é a leitura "para valer". Assim como já revelado, a verdadeira leitura não é aquela que vai ser primeiro ensinada e aprendida, para depois ser exercitada. Aliás, pode-se dizer que na escola, infelizmente, talvez seja o único lugar em que isso ainda aconteça, pois, conforme já afirmado “ $[\ldots]$ a vida cotidiana está cheia de oportunidades de leitura” (JOLIBERT, 1994, p. 31).

Em concordância com a autora, pode-se afirmar que, no contexto da escola, muitos são os motivos e situações que provocam a necessidade de leitura e estimulam as crianças a buscarem ler "para valer” enunciados completos. Para ler no sentido pleno, não basta ter o conhecimento do sistema gráfico fragmentado para que posteriormente ele seja utilizado. É por meio da própria vivência da leitura de textos completos, 
Revista Educação e Políticas em Debate - v. 10, n. 2, p. 784-800, mai./ago. 2021 - ISSN 2238-8346 carregados de sentidos e discursos alheios, com um objetivo específico, que o sujeito aprende realmente a ler. Ao exemplificar alguns dos diversos objetivos possíveis de leitura na escola, Jolibert (1994, p. 31$)$ indica:

Ler:

-para responder à necessidade de viver com os outros, na sala de aula e na escola;

-para se comunicar com o exterior;

-para descobrir as informações das quais se necessita;

-para fazer (brincar, construir, levar a termo um projeto-empreendimento); -para alimentar e estimular o imaginário;

-para documentar-se no quadro de uma pesquisa em andamento.

Mediante situações como essas elencadas pela autora, ou ainda por "caçadas" como as realizadas nessa pesquisa, as crianças poderão vivenciar situações reais de leitura. Provocadas pelo interesse em "ler de verdade", exercitar a leitura de “[... textos autênticos, completos, em situações de uso e relacionados aos projetos, necessidades e desejos em pauta" (JOLIBERT; JACOB, 2006, p. 183), as crianças poderão avançar em seus processos de apropriação da língua escrita, apropriando-se no mesmo processo das infinitas possibilidades de transformação e de autotransformação que a cultura escrita oferece.

Finalizada a apresentação da estratégia Ler para encontrar concretizada na perspectiva de uma alfabetização discursiva será possível apresentar as considerações finais sobre esse processo investigativo.

\section{Considerações finais}

Em consonância com o aporte teórico e com as análises dos dados que as experiências em campo oportunizaram, conclui-se que a leitura só pode ser significativa se for realmente utilizada na sua forma integral de ser. Por meio do uso de textos, foi possível presenciar a apropriação do ato cultural de ler pelas crianças nas situações de uso.

Não faria sentido estudar como são as escritas de textos poéticos, jornais, HQs e tantos outros gêneros para somente depois poder manusear, utilizar, se apropriar de seus sentidos e significados. Diferentemente dessa lógica, na atividade aqui apresentada, os textos foram ofertados às crianças e foi por meio das relações estabelecidas com eles à medida em que iam circulando, que as crianças se apropriaram de suas formas e de seus contextos, foi assim que a atividade com a leitura permeou o trabalho pedagógico do primeiro ao último dia de aula do ano letivo em que foi desenvolvida a pesquisa. 
Revista Educação e Políticas em Debate - v. 10, n. 2, p. 784-800, mai./ago. 2021 - ISSN 2238-8346

\section{Referências}

ABREU, M. M. de O. Ensino fundamental de nove anos: implicações no processo de alfabetização e letramento. São Paulo: Junqueira \& Marin, 2012.

ARENA, D. B. Leitura no espaço da biblioteca do espaço escolar. In: SOUZA, R. J. de (Org.). Biblioteca escolar e práticas educativas: o mediador em formação. Campinas: Mercado de Letras, 2009. p. $157-185$.

BAJARD, É. Da escuta de textos à leitura. São Paulo: Cortez, 2007.

BAKHTIN, M. Estética da criação verbal. Trad. Paulo Bezerra. 1. ed. São Paulo: Martins Fontes, 2003.

BAKHTIN, M.; VOLOCHÍNOV, V. Marxismo e filosofia da linguagem: problemas fundamentais do método sociológico na ciência da linguagem. Trad. Michel Lahud e Yara F. Vieira. 16. ed. São Paulo: Hucitec, 2014.

BAKHTIN, M.; VOLOCHÍNOV, V. Marxismo e filosofia da linguagem: problemas fundamentais do método sociológico na ciência da linguagem. Trad. Sheila Grillo e Ekaterina V. Américo. 1. ed. São Paulo: Editora 34, 2017.

JOLIBERT, J. Formando crianças leitoras. Trad. Bruno C. Magne. Porto Alegre: Artes Médicas, 1994.

JOLIBERT, J.; JACOB, J. Além dos muros da escola: a escrita como ponte entre os alunos e comunidade. Tradução Ana Maria Netto Machado. Porto Alegre: Artmed, 2006.

MELLO, S. A. A Apropriação da Escrita como Instrumento Cultural Complexo. In: MENDONÇA, S. G. de L. e MILLER, S. (Orgs.). Vigotski e a Escola Atual: fundamentos teóricos e implicações pedagógicas. Araraquara: J.M. Editora e Cultura Acadêmica Editora, 2010. $2^{\mathrm{a}}$ edição.

SMITH, F. Compreendendo a leitura: uma análise psicolinguística da leitura e do aprender a ler. Porto Alegre: Artes Médicas, 1989.

VYGOTSKY, L. S. A Construção do Pensamento e da Linguagem. 2. ed. Tradução Paulo Bezerra. São Paulo: WMF Martins Fontes, 2009. 